\title{
Patient and physician evaluation of the severity of acute asthma exacerbations
}

J.A. Atta, M.P.T. Nunes, C.H.F. Fonseca-Guedes, L.A. Avena, M.T. Borgiani, R.F. Fiorenza and M.A. Martins
Departamento de Clínica Médica, Faculdade de Medicina, Universidade de São Paulo, São Paulo, SP, Brasil

\author{
Correspondence \\ M.A. Martins \\ Faculdade de Medicina, USP \\ Av. Dr. Arnaldo, 455, Sala 1216 \\ 01246-903 São Paulo, SP \\ Brasil \\ Fax: +55-11-3083-0827/3085-0992 \\ E-mail: mmartins@usp.br
}

Research supported by CNPq,

FAPESP and PRONEX-MCT.

Received July 15, 2003

Accepted April 28, 2004

\section{Abstract}

We studied the ability of patients not experienced in the use of peak expiratory flow meters to assess the severity of their asthma exacerbations and compared it to the assessment of experienced clinicians. We also evaluated which data of physical examination and medical history are used by physicians to subjectively evaluate the severity of asthma attacks. Fifty-seven adult patients (15 men and 42 women, with a mean $( \pm$ SD) age of $37.3 \pm 14.5$ years and $24.0 \pm 17.9$ years of asthma symptoms) with asthma exacerbations were evaluated in a University Hospital Emergency Department. Patients and physicians independently evaluated the severity of the asthma attack using a linear scale. Patient score, physician score and forced expiratory volume at the first second $\left(\mathrm{FEV}_{1}\right)$ were correlated with history and physical examination variables, and were also considered as dependent variables in multiple linear regression models. $\mathrm{FEV}_{1}$ correlated significantly with the physician score $(\mathrm{rho}=0.42, \mathrm{P}=0.001)$, but not with patient score $(\mathrm{rho}=$ $0.03 ; \mathrm{P}=0.77$ ). Use of neck accessory muscles, expiratory time and wheezing intensity were the explanatory variables in the $\mathrm{FEV}_{1}$ regression model and were also present in the physician score model. We conclude that physicians evaluate asthma exacerbation severity better than patients and that physician's scoring of asthma severity correlated significantly with objective measures of airway obstruction $\left(\mathrm{FEV}_{1}\right)$. Some variables (the use of neck accessory muscles, expiratory time and wheezing intensity) persisted as explanatory variables in physician score and $\mathrm{FEV}_{1}$ regression models, and should be emphasized in medical schools and emergency settings.

\section{Introduction}

Asthma is a chronic airway inflammatory disease characterized by symptoms of wheezing, chest tightness and breathlessness (1). Patients with asthma also present episodic airway obstruction. In the presence of an
Key words

- Asthma

- Asthma attack

- Pulmonary function tests

- Dyspnea acute exacerbation of asthma, the physician must know the severity of airway obstruction in order to provide appropriate therapy and to identify life-threatening episodes.

In the emergency room, physicians usually assess the severity of airway obstruction using symptoms and physical signs such as respira- 
tory distress, wheezing, contraction of accessory respiratory muscles, the presence of pulsus paradoxus, tachycardia, and tachypnea. However, it has been suggested that physical findings are not reliable indicators of the severity of airway obstruction (2). Kelsen et al. (3) observed, in an emergency room, that measured airway obstruction was only modestly increased when patients had sufficiently improved to be discharged using clinical criteria (3). A clinically significant proportion of asthmatic patients substantially underestimate disease severity and thereby may be at risk of increased morbidity and mortality (4).

Current recommendations are that an objective measure of airway obstruction such as forced expiratory volume $\left(\mathrm{FEV}_{1}\right)$ or peak expiratory flow rate (PEFR) should be used, in addition to symptoms and physical findings, in the initial evaluation and assessment of adequacy of treatment of asthma exacerbations in the emergency room (5).

The ability of patients to detect the severity of their own asthma exacerbation has been less well studied. Shim and Williams Jr. (6) observed that patients experienced in the use of peak flow meters were more accurate in estimating their own PEFR than experienced physicians. However, a substantial number of patients with asthma do not use peak flow meters regularly. We reasoned that patient assessment of the severity of asthma exacerbation would add relevant information to the evaluation of acute airway obstruction.

The purposes of the present investigation were to determine the ability of patients not experienced in peak flow meter use to assess the severity of their own asthma exacerbations and to compare this to the assessment of experienced clinicians, using $\mathrm{FEV}_{1}$ as the gold standard of measurement of the severity of airway obstruction. We also evaluated which data of the physical examination and medical history are used by doctors to subjectively evaluate the severity of asthma attacks.

\section{Subjects and Methods}

The Research Ethics Committee of the School of Medicine, University of São Paulo, approved our protocol. All patients gave written informed consent to participate in the study.

\section{Subjects}

We studied 57 patients (15 men and 42 women) admitted to the emergency room of the Hospital das Clínicas, University of São Paulo, with an acute attack of asthma, over a period of 18 months. Patient mean $( \pm \mathrm{SD})$ age was $37.3 \pm 14.5$ years (range: $16-72$ years). All patients had a history of asthma $(24.0 \pm 17.9$ years of symptoms). The criteria for inclusion in the study were: 1) past history of asthma, diagnosed according to American Thoracic Society (7) criteria and previous doctor diagnosis of asthma; 2 ) absence of symptoms suggestive of chronic bronchitis or chronic obstructive pulmonary disease, such as chronic cough; 3 ) no previous experience in the use of peak flow meters; 4) age range from 16 to 70 years; 5) initial $\mathrm{FEV}_{1}$ lower than $80 \%$ of predicted and $\mathrm{FEV}_{1}$ /forced vital capacity lower than $80 \%$.

We also excluded patients whose symptoms had developed after years of cigarette smoking or who could not perform the spirometric maneuvers, either due to intense dyspnea or to lack of understanding of the spirometric maneuvers. Only $19.3 \%$ of the patients had used corticosteroids during the present crisis before admission to the hospital.

After being asked questions by the researchers to ascertain the asthma diagnosis and to exclude other causes of airway obstruction, the patient was submitted to spirometry, the history was taken and physical examination was performed. The same person performed all the spirometric studies, and physicians with at least 10 years of clinical experience did the medical evaluation. Neither the physicians nor the patients 
were aware of the spirometric results. The patients were medicated according to the routine of the service.

\section{History variables}

The background information asked was duration of asthma, occupational exposure, hospital admissions in the previous year, previous intensive care unit admissions, previous mechanical ventilation due to asthma crisis, cigarette smoking status, use of inhaled or oral steroids, and duration of the present asthma attack. The symptoms elicited were coughing, presence of pulmonary secretion, thoracic pain or discomfort, and intensity of dyspnea sensation. When the history was completed, patients were asked to grade the severity of their attack on a linear scale, with the worst possible scenario at the left end and the best possible at the right end ("patient score"), adapted from Borg's scale of breathlessness (8).

\section{Physical examination variables}

The variables studied were pulse, systolic and diastolic blood pressure, pulsus paradoxus, respiratory frequency, expiratory time and forced expiratory time (in seconds, measured with a chronometer, mean of three measures), use of neck accessory muscles, presence of intercostal retraction, nares flaring, cyanosis, intensity of breath sounds, wheezing, wheezing in forced expiration, and presence of rhonchi. At the end of the physical examination the physician graded the severity of the asthma exacerbation using another linear scale, identical to the one used by patients ("physician score"). The physician who did the clinical evaluation and graded the severity of the asthma attack was unaware of the patient self-evaluation.

\section{Spirometry}

The same person performed all the spiro- metric studies, according to American Thoracic Society standardization (9), using a portable Koko spirometer and software (Pds Instrumentation, Inc., Louisville, CO, USA).

\section{Statistical analysis}

We calculated the pair-wise Spearman correlation coefficients (rank order coefficient, rho) for nonparametric values between the physician score and the variables in the study (both history and physical examination). We also calculated Spearman correlation coefficients for the patient score and the $\mathrm{FEV}_{1}$. The physician score, the patient score and $\mathrm{FEV}_{1}$ were considered to be dependent variables in multiple linear regression models, using a stepwise forward procedure, with the explanatory variables (history and physical examination for the physician or just history for the patient and just physical examination for the $\mathrm{FEV}_{1}$ ) added one by one, according to their correlation coefficient values (down from the highest). At each step a new variable was added to the model if the $\mathrm{P}$ value related to its coefficient was less than 0.10 , the $\mathrm{P}$ values of the previous variables did not rise above 0.10 , and this variable increased the model adjusted R square. We also tested the possible interactions between significant explanatory variables.

\section{Results}

The present asthma exacerbation lasted $79.0 \pm 125.1 \mathrm{~h}$ (range 1-720 h). $\mathrm{FEV}_{1}$ values were $40.3 \pm 17.0 \%$ (range $22.0-75.0 \%$ ) and peak expiratory flow values were $33.0+$ $14.0 \%$ (range 19.0-75.5\%).

Table 1 shows the Spearman correlation coefficients (rho) between all the variables studied and physician score (from 0 to 10 ), patient score (from 0 to 10) and $\mathrm{FEV}_{1}$ (\% of predicted). The physician score correlated well with $\mathrm{FEV}_{1}$, with a rho of $0.42(\mathrm{P}=$ 0.001; Figure 1A), and the patient score, 
Figure 1. Relationship between severity scores of asthma exacerbation evaluated by physicians (A) and patients (B) and forced expiratory volume at the first second $\left(F E V_{1}\right.$; \% predicted). Scores range from 0 (more severe) to 10 (less severe). The correlation coefficients, determined by the Spearman method, were 0.42 for physician score $(P=0.001)$ and 0.03 for patient score $(P=$ $0.77)$.

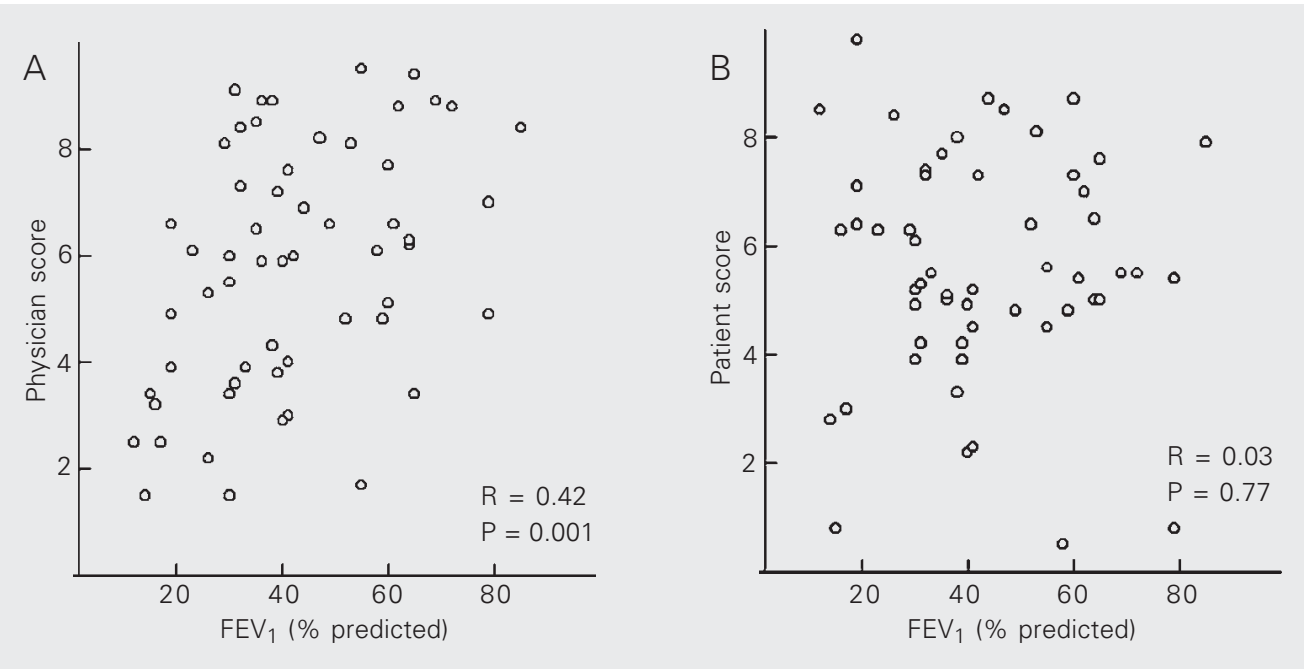

Table 1. Correlation coefficients between physician score, patient score, forced expiratory volume at the first second $\left(F E V_{1}\right)$, and clinical variables.

\begin{tabular}{|c|c|c|c|}
\hline & Physician score & Patient score & $\mathrm{FEV}_{1}(\%$ predicted $)$ \\
\hline Physician score & - & $0.39 *$ & $0.42 * *$ \\
\hline Patient score & $0.39 * *$ & - & 0.04 \\
\hline Use of neck accessory muscles & $-0.47 * *$ & -0.17 & $-0.44 * *$ \\
\hline Expiratory time & $-0.44 * *$ & $-0.33^{*}$ & $-0.29 *$ \\
\hline Dyspnea & $-0.42 * *$ & $-0.45^{* *}$ & -0.13 \\
\hline Previous year hospital admissions & $-0.41 * *$ & -0.10 & -0.16 \\
\hline Pulsus paradoxus $>10 \mathrm{mmHg}$ & $-0.39 * *$ & -0.06 & $-0.27^{*}$ \\
\hline Wheezing & $-0.31^{*}$ & -0.11 & $-0.44 * *$ \\
\hline Intercostal retraction & $-0.31^{*}$ & -0.19 & -0.15 \\
\hline Previous mechanical ventilation & $-0.31 *$ & -0.15 & -0.11 \\
\hline Vesicular sounds & $-0.29 *$ & -0.05 & 0.00 \\
\hline Nares flaring & $-0.27^{*}$ & $-0.30 *$ & 0.04 \\
\hline Use of steroids & -0.25 & -0.18 & 0.05 \\
\hline Diastolic blood pressure & -0.25 & -0.20 & -0.23 \\
\hline Duration of asthma & 0.24 & 0.06 & 0.15 \\
\hline Cyanosis & -0.23 & $-0.28^{*}$ & -0.07 \\
\hline Systolic blood pressure & -0.20 & -0.09 & -0.18 \\
\hline ICU admissions & -0.19 & -0.05 & -0.05 \\
\hline Pulse & -0.18 & -0.24 & -0.20 \\
\hline Cigarette smoking & -0.16 & -0.05 & -0.21 \\
\hline Forced expiratory time & 0.16 & 0.07 & -0.03 \\
\hline Ronchi & -0.14 & -0.14 & -0.02 \\
\hline Cough & 0.13 & 0.00 & 0.23 \\
\hline Respiratory frequency & -0.11 & 0.15 & -0.16 \\
\hline Gender & -0.11 & 0.15 & 0.06 \\
\hline Wheezing in forced expiration & -0.10 & 0.07 & -0.31 \\
\hline Age & -0.07 & 0.05 & 0.05 \\
\hline Thoracic pain & 0.04 & -0.19 & -0.04 \\
\hline Secretion & 0.04 & 0.21 & -0.05 \\
\hline Occupational exposure & -0.01 & -0.24 & -0.02 \\
\hline
\end{tabular}

$\mathrm{ICU}=$ intensive care unit. ${ }^{*} P<0.05$ and ${ }^{*} P<0.01$, obtained by the Spearman method. 


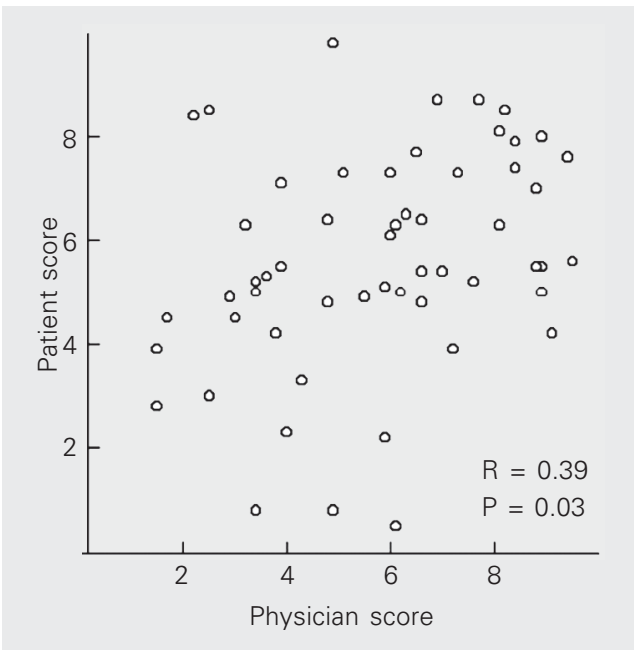

Figure 2. Relationship between severity scores of asthma exacerbation given by physicians and patients. Scores range from 0 (more severe) to 10 (less severe). The correlation coefficient, determined by the Spearman method, was $0.39(P=0.03)$

although correlating with the physician score (rho $=0.39, \mathrm{P}=0.03$; Figure 2 ), did not correlate with $\mathrm{FEV}_{1}$ (rho $=0.03, \mathrm{P}=0.77$; Figure 1B). The variables with a significant correlation coefficient in relation to the patient score were use of neck accessory muscles, expiratory time, intensity of dyspnea, hospital admissions in the preceding year, pulsus paradoxus higher than $10 \mathrm{mmHg}$, intensity of wheezing, intercostal retractions, history of need for mechanical ventilation due to asthma attacks, intensity of vesicular sounds, and nares flaring.

Table 2 presents the history and physical examination variables in relation to the patient score, with their descriptive measures (mean, standard error and number of patients in each category). In one patient it was not possible to evaluate the presence of pulsus paradoxus for technical reasons.

When we did a stepwise regression analysis using physician score as the dependent variable, use of neck accessory muscles, expiratory time, hospital admissions in the previous year, pulsus paradoxus, wheezing, and nares flaring remained in the model, with an adjusted $\mathrm{R}^{2}$ of 0.53 (Table 3 ).
Table 2. Categorical variables obtained in medical history and physical examination and physician score.

\begin{tabular}{|c|c|c|c|}
\hline & $\begin{array}{l}\text { Mean } \\
\text { score }\end{array}$ & $\begin{array}{l}\text { Standard } \\
\text { deviation }\end{array}$ & $\begin{array}{c}\text { Number of } \\
\text { patients }\end{array}$ \\
\hline \multicolumn{4}{|c|}{ Use of neck accessory muscles } \\
\hline No & 6.52 & 2.02 & 40 \\
\hline Yes & 4.10 & 2.00 & 17 \\
\hline \multicolumn{4}{|c|}{ Previous year hospital admissions } \\
\hline No & 6.54 & 2.20 & 35 \\
\hline Yes & 4.62 & 1.93 & 22 \\
\hline \multicolumn{4}{|l|}{ Pulsus paradoxus } \\
\hline No & 6.30 & 2.07 & 44 \\
\hline Yes & 4.08 & 2.29 & 13 \\
\hline \multicolumn{4}{|l|}{ Wheezing } \\
\hline Absent/little & 6.83 & 2.38 & 17 \\
\hline Moderate/intense & 5.36 & 2.12 & 40 \\
\hline \multicolumn{4}{|l|}{ Nares flaring } \\
\hline No & 5.96 & 2.26 & 53 \\
\hline Yes & 3.60 & 1.73 & 4 \\
\hline \multicolumn{4}{|l|}{ Dyspnea } \\
\hline Absent/little & 7.10 & 1.89 & 21 \\
\hline Moderate/severe & 5.10 & 2.23 & 36 \\
\hline \multicolumn{4}{|l|}{ Intercostal retraction } \\
\hline No & 6.19 & 2.25 & 45 \\
\hline Yes & 4.33 & 1.83 & 12 \\
\hline \multicolumn{4}{|c|}{ Previous mechanical ventilation } \\
\hline No & 6.01 & 2.24 & 50 \\
\hline Yes & 3.96 & 1.87 & 7 \\
\hline \multicolumn{4}{|l|}{ Vesicular sounds } \\
\hline Normal & 6.36 & 2.25 & 32 \\
\hline Diminished & 5.08 & 2.18 & 25 \\
\hline \multicolumn{4}{|l|}{ Use of steroids } \\
\hline No & 6.08 & 2.31 & 46 \\
\hline Yes & 4.63 & 1.81 & 11 \\
\hline \multicolumn{4}{|l|}{ Cyanosis } \\
\hline No & 6.01 & 2.28 & 44 \\
\hline Yes & 4.86 & 2.12 & 13 \\
\hline \multicolumn{4}{|l|}{ ICU admissions } \\
\hline No & 5.92 & 2.29 & 52 \\
\hline Yes & 4.46 & 2.03 & 5 \\
\hline \multicolumn{4}{|l|}{ Cigarette smoking } \\
\hline No & 6.16 & 2.41 & 30 \\
\hline Yes & 5.40 & 2.12 & 27 \\
\hline \multicolumn{4}{|l|}{ Ronchi } \\
\hline No & 5.98 & 2.46 & 39 \\
\hline Yes & 5.40 & 1.86 & 18 \\
\hline \multicolumn{4}{|l|}{ Cough } \\
\hline No & 5.53 & 2.12 & 26 \\
\hline Yes & 6.07 & 2.46 & 31 \\
\hline \multicolumn{4}{|l|}{ Gender } \\
\hline Male & 6.25 & 2.06 & 15 \\
\hline Female & 5.64 & 2.37 & 42 \\
\hline \multicolumn{4}{|c|}{ Wheezing in forced expiration } \\
\hline Absent/little & 6.17 & 2.45 & 15 \\
\hline Moderate/intense & 5.66 & 2.24 & 42 \\
\hline Thoracic pain & & & \\
\hline No & 5.65 & 2.41 & 15 \\
\hline Yes & 5.88 & 2.29 & 42 \\
\hline Secretion & & & \\
\hline No & 5.64 & 2.38 & 17 \\
\hline Yes & 5.90 & 2.30 & 40 \\
\hline Occupational exposu & & & \\
\hline No & 5.81 & 2.29 & 40 \\
\hline Yes & 5.77 & 2.36 & 17 \\
\hline
\end{tabular}

$\mathrm{ICU}=$ intensive care unit. 
Table 3. Final stepwise regression models using physician score, patient score, and forced expiratory volume at the first second $\left(\mathrm{FEV}_{1}\right)$ as dependent variables.

\begin{tabular}{|c|c|c|c|c|}
\hline & Coefficient & Standard error & $P$ value & Adjusted $\mathrm{R}$ square \\
\hline \multicolumn{5}{|l|}{ Physician score (0-10) } \\
\hline Use of accessory neck muscles & -1.66 & 0.51 & 0.002 & 0.22 \\
\hline Expiratory time & -0.69 & 0.39 & 0.078 & 0.36 \\
\hline Previous year hospital admissions & -1.42 & 0.48 & 0.005 & 0.44 \\
\hline Pulsus paradoxus $>10 \mathrm{mmHg}$ & -1.15 & 0.53 & 0.034 & 0.47 \\
\hline Wheezing & -1.09 & 0.49 & 0.031 & 0.50 \\
\hline Nares flaring & -1.76 & 0.84 & 0.040 & 0.53 \\
\hline \multicolumn{5}{|l|}{ Patient score (0-10) } \\
\hline Dyspnea & -1.98 & 0.59 & 0.001 & 0.16 \\
\hline \multicolumn{5}{|l|}{$\mathrm{FEV}_{1}(\%$ predicted) } \\
\hline Use of accessory neck muscles & -10.20 & 4.86 & 0.041 & 0.15 \\
\hline Wheezing & -14.94 & 4.89 & 0.004 & 0.26 \\
\hline Expiratory time & -6.58 & 3.48 & 0.062 & 0.28 \\
\hline
\end{tabular}

Table 4. History concerning categorical variables and patient score.

\begin{tabular}{|c|c|c|c|}
\hline & Mean score & Standard deviation & Number of patients \\
\hline \multicolumn{4}{|l|}{ Dyspnea } \\
\hline Absent/little & 6.85 & 1.49 & 21 \\
\hline Moderate/severe & 4.87 & 2.36 & 36 \\
\hline \multicolumn{4}{|c|}{ Previous year hospital admissions } \\
\hline No & 5.69 & 2.38 & 35 \\
\hline Yes & 5.42 & 2.12 & 22 \\
\hline \multicolumn{4}{|c|}{ Previous mechanical ventilation } \\
\hline No & 5.66 & 2.35 & 50 \\
\hline Yes & 5.09 & 1.68 & 7 \\
\hline \multicolumn{4}{|l|}{ Use of steroids } \\
\hline No & 5.71 & 2.46 & 46 \\
\hline Yes & 5.08 & 1.14 & 11 \\
\hline \multicolumn{4}{|l|}{ ICU admissions } \\
\hline No & 5.59 & 2.33 & 52 \\
\hline Yes & 5.54 & 1.69 & 5 \\
\hline \multicolumn{4}{|l|}{ Cigarette smoking } \\
\hline No & 5.66 & 2.40 & 30 \\
\hline Yes & 5.52 & 2.15 & 27 \\
\hline \multicolumn{4}{|l|}{ Cough } \\
\hline No & 5.69 & 1.99 & 26 \\
\hline Yes & 5.47 & 2.55 & 31 \\
\hline \multicolumn{4}{|l|}{ Gender } \\
\hline Male & 5.07 & 2.09 & 15 \\
\hline Female & 5.77 & 2.33 & 42 \\
\hline \multicolumn{4}{|l|}{ Thoracic pain } \\
\hline No & 6.33 & 1.58 & 15 \\
\hline Yes & 5.30 & 2.46 & 42 \\
\hline \multicolumn{4}{|l|}{ Secretion } \\
\hline Absent & 5.09 & 2.11 & 17 \\
\hline Present & 5.79 & 2.36 & 40 \\
\hline \multicolumn{4}{|c|}{ Occupational exposure } \\
\hline No & 5.92 & 2.35 & 40 \\
\hline Yes & 4.81 & 1.90 & 17 \\
\hline
\end{tabular}


Table 4 shows the descriptive measures of history categoric variables in relation to patient score. Although some variables correlated with patient score (dyspnea, expiratory time, nares flaring, and cyanosis), only dyspnea persisted in the stepwise regression analysis, with an adjusted $\mathrm{R}^{2}$ of 0.16 (Table 3).

Table 5 shows the descriptive measures of the physical examination categoric variables in relation to $\mathrm{FEV}_{1}$. Table 3 shows the stepwise regression analysis for $\mathrm{FEV}_{1}$, with an adjusted $R^{2}$ of 0.28 . The significant variables in this model were use of neck accessory muscles, wheezing and expiratory time.

\section{Discussion}

In the present study, we observed that experienced physicians better perceived the severity of asthma attacks than patients. In addition, the physicians' score of severity correlated significantly with the degree of airway obstruction measured by spirometry $\left(\mathrm{FEV}_{1}\right)$, although the correlation coefficient was only $0.42(\mathrm{P}=0.001)$.

Only dyspnea was significantly correlated with patient self-evaluation of asthma severity (adjusted $\mathrm{R}^{2}=0.16$, stepwise regression) in our study. It is possible that patients use other criteria to determine asthma severity besides the variables measured in our study. However, we did not find any significant correlation between patients' score and $\mathrm{FEV}_{1}$. Interestingly, Kunitoh et al. (10) demonstrated that among many variables only the degree of dyspnea rated on a Borg's scale remained predictive to discriminate hypoxia in acute asthma attacks, and that dyspnea was the only remaining predictor of hospitalization, with a sensitivity of $75 \%$ and a specificity of $78 \%$ (11). Morris et al. (12) studied asthmatic patients, comparing selfperceived severity of asthma and severity

\begin{tabular}{|c|c|c|c|}
\hline & Mean value of $F E V_{1}$ & Standard deviation & Number of patients \\
\hline \multicolumn{4}{|c|}{ Use of neck accessory muscles } \\
\hline No & 47.03 & 17.25 & 40 \\
\hline Yes & 31.24 & 15.65 & 17 \\
\hline \multicolumn{4}{|l|}{ Wheezing } \\
\hline Absent/little & 54.71 & 15.68 & 17 \\
\hline Moderate/intense & 37.05 & 16.68 & 40 \\
\hline \multicolumn{4}{|c|}{ Pulsus paradoxus >10 mmHg } \\
\hline No & 45.12 & 18.44 & 44 \\
\hline Yes & 33.62 & 15.38 & 13 \\
\hline \multicolumn{4}{|l|}{ Intercostal retraction } \\
\hline Absent & 43.73 & 18.47 & 45 \\
\hline Present & 37.00 & 16.68 & 12 \\
\hline \multicolumn{4}{|l|}{ Vesicular sounds } \\
\hline Normal & 42.09 & 17.41 & 32 \\
\hline Diminished & 42.60 & 19.47 & 25 \\
\hline \multicolumn{4}{|l|}{ Cyanosis } \\
\hline Absent & 43.23 & 18.55 & 44 \\
\hline Present & 39.23 & 17.20 & 13 \\
\hline \multicolumn{4}{|l|}{ Ronchi } \\
\hline No & 43.10 & 19.40 & 39 \\
\hline Yes & 40.61 & 15.57 & 18 \\
\hline \multicolumn{4}{|c|}{ Wheezing in forced expiration } \\
\hline Absent/little & 51.73 & 15.86 & 15 \\
\hline Moderate/intense & 38.95 & 17.92 & 42 \\
\hline
\end{tabular}


scores with peak flow, and detected a significant association.

Shim and Williams Jr. (6) studied asthmatic patients who had used the Wright Peak Flow Meter in the past. These patients were asked to guess the values of their PEFR. Sixty-three percent of the estimates were within $20 \%$ of the measured value. In contrast, when physicians who took 3 to $5 \mathrm{~min}$ to examine the patient guessed the PEFR value, only $44 \%$ were within $20 \%$ of the measured value. Experienced patients were far more accurate in assessing their own PEFR than were the physicians. The main difference between our study and the study of Shim and Williams Jr. is that our patients were not experienced in measurement of airway obstruction. This raises the possibility that the ability to self-evaluate the severity of asthma attacks can be improved by training.

Boulet et al. (13) and Burdon et al. (14) using a histamine challenge, observed that patients with asthma showed a wide interindividual variability in the perception of airway obstruction. Rubinfeld and Pain (15) reported that airway resistance had to be increased substantially before symptoms were present and that $15 \%$ of the patients were unable to identify the presence of marked airway obstruction. Burki et al. (16) found that patients with asthma varied markedly in their ability to detect added resistive loads. In addition, Sont et al. (17) showed that the severity of breathlessness in patients with asthma is greater during hypertonic saline than during methacholine challenge at any given level of airway obstruction, suggesting that the intensity of asthma symptoms depends on the mechanisms involved in acute airway obstruction.

In the present study we also assessed the variables that influenced the physician's global evaluation of exacerbation severity. Use of neck accessory muscles, expiratory time, dyspnea, pulsus paradoxus, intensity of wheezing, intercostal retraction, decreased vesicular sounds, nares flaring, previous year hospital admissions, and previous orotracheal intubations were correlated with physicians' score (Table 1). Among these variables, in the stepwise regression, use of neck accessory muscles, expiratory time, hospital admissions in the previous year, pulsus paradoxus, intensity of wheezing, and nares flaring remained in the physician score model. However, among these variables, only use of neck accessory muscles, expiratory time, pulsus paradoxus, and intensity of wheezing were significantly correlated with objective measurement of airway obstruction $\left(\mathrm{FEV}_{1}\right)$. Pulsus paradoxus has been suggested to be a reliable indicator of the degree of airway obstruction, but it is not inevitably present when expiratory flow rates are very low $(3,18-20)$.

It is interesting to note that a sign more used by pediatricians (nares flaring) correlates significantly with physician score. Expiratory time is not usually recorded because of technical difficulties in performing the procedure (the need for a chronometer, a single measure may be unreliable), but expiratory time was correlated with both the physician and the $\mathrm{FEV}_{1}$ models, emphasizing the need to attribute a greater value to this sign. Although we did not evaluate the severity of the disease, but only the severity of the current crisis of the patient, it is interesting to note that some variables indicating disease severity (hospital admission, need for mechanical ventilation) correlated significantly with physician score.

We observed a significant correlation between physician global evaluation of the acute attack severity and $\mathrm{FEV}_{1}$. It is important to note that although $\mathrm{FEV}_{1}$ has been used as a "gold standard" to determine the severity of airway obstruction in acute asthma, there are other factors that substantially influence the prognosis of asthma attacks such as response to bronchodilators (21). In a study by Bailey et al. (22), scales using symptoms and clinical outcomes such as hospitalization 
and need for medication were compared to a judgmental scale by physicians, with PEFR as the objective measure, showing a significant correlation.

The ability of experienced physicians to assess the severity of asthma attacks has been previously investigated. Kelsen et al. (3) reported that measured airway obstruction was only modestly relieved in a group of patients treated in an emergency room who met conventional clinical criteria for discharge. In our study, in 15 patients $(26 \%$ of total) the $\mathrm{FEV}_{1}$ was lower than $40 \%$ predicted but the physicians gave a score $\geq 5$, underestimating the severity of the asthma attack. This observation implies that even experienced physicians cannot identify all patients with severe airway obstruction using clinical criteria only.

One limitation of the present study was that we did not know the previous best $\mathrm{FEV}_{1}$ values of the patients studied and so we were not able to define the severity of airway obstruction as a percentage of the personal best $\mathrm{FEV}_{1}$. Since our purpose was to study patients not experienced in the regular use of peak flow meters, many of the patients studied were not under regular follow-up and, therefore, had not performed a spirometry in the past year.

We did not exclude patients who smoked, unless asthma developed after the beginning of smoking or patients had chronic cough or other symptoms suggestive of chronic bron- chitis or chronic obstructive pulmonary disease. We observed that smoking status did not influence significantly either patient or doctor evaluation of the severity of the asthma attack, and did not correlate with the reduction in $\mathrm{FEV}_{1}$.

The present study indicates that in the initial evaluation of the severity of asthma exacerbations, an objective measurement of airway obstruction must be used in conjunction with a carefully structured clinical evaluation. Patients' self-perception of the severity of their attack does not seem to add significant information to this initial evaluation. Some variables of the physical examination are very important for the determination of asthma attack severity, such as use of neck accessory muscles, expiratory time and intensity of wheezing, and so should be emphasized more in medical schools and emergency settings.

\section{Acknowledgments}

The authors thank Gleice M. Conceição for helpful advice concerning statistical analysis and Joaquim E. Vieira for a critical review of the manuscript. The authors are grateful to Daniela Calderaro, Cláudia R. Notrispe, Sílvia M.A. Shimomoto, Marcia M. Morales, and Patrícia P. Andrade e Silva for help with the study design and data collection.

\section{References}

1. Global Initiative for Asthma (1995). Global Strategy for Asthma Management and Prevention. NHLBI/WHO Workshop Report. National Institutes of Health, National Heart, Lung, and Blood Institute, Bethesda, MD, USA.

2. McFadden Jr ER, Kiser R \& Degroot WJ (1973). Acute bronchial asthma. New England Journal of Medicine, 288: 221-225.

3. Kelsen SG, Kelsen DP, Fleegler BF, Jones RC \& Rodman T (1978). Emergency room assessment and treatment of patients with acute asthma. Adequacy of the conventional approach. American Journal of Medicine, 6: 622-628.

4. Nguyen BP, Wilson SR \& German DF (1996). Patient's perceptions compared with objective rating of asthma severity. Annals of
Allergy, Asthma, and Immunology, 77: 209-215.

5. British Thoracic Society, Research Unit of the Royal College of Physicians of London, King's Fund Centre, National Asthma Campaign (1990). Guidelines for management of asthma in adults: II acute severe asthma. British Medical Journal, 301: 797-800.

6. Shim CS \& Williams Jr MH (1980). Evaluation of the severity of asthma: patients versus physicians. American Journal of Medicine, 68: 11-13.

7. Guidelines for the Diagnosis and Management of Asthma (1997). Expert Panel Report II. National Asthma Education and Prevention Program. NIH Publication No. 97-4051; National Heart, Blood and Lung Institute, Bethesda, MD, USA. 
8. Borg GAV (1982). Psychological bases of perceived exertion. Medicine and Science in Sports and Exercise, 14: 377-381.

9. Official Statement of the American Thoracic Society (1995). Committee on Proficiency Standards for Clinical Pulmonary Function Laboratories. American Journal of Respiratory and Critical Care Medicine, 152: 1107-1136.

10. Kunitoh H, Watanabe K \& Sajima $Y$ (1994). Clinical features to predict hypoxia and/or hypercapnia in acute asthma attacks. Journal of Asthma, 31: 401-407.

11. Kunitoh $H$, Nagatomo A, Okamoto $H$, Watanabe $K$ \& Sajima $Y$ (1996). Predicting the need for hospital admission in patients with acute bronchial asthma. Journal of Asthma, 36: 105-112.

12. Morris NV, Abramson MJ, Rosier MJ \& Strasser RP (1996). Assessment of the severity of asthma in a family practice. Journal of Asthma, 33: 425-439.

13. Boulet LP, LeBlanc P \& Turcotte $H$ (1994). Perception scoring of induced bronchoconstriction as an index of awareness of asthma symptoms. Chest, 105: 1430-1433.

14. Burdon JGW, Juniper EF, Killian KJ, Hargreave FE \& Campbell EJ (1982). The perception of breathlessness in asthma. American Review of Respiratory Diseases, 126: 825-828.

15. Rubinfeld AR \& Pain MC (1976). Perception of asthma. Lancet, 1
(7965): 882-884

16. Burki NK, Mitchell K, Chaudhary BA \& Zechman FW (1978). The ability of asthmatic patients to detect added resistive loads. American Review of Respiratory Diseases, 117: 71-75.

17. Sont JK, Booms P, Bel EH, Vandenbroucke JP \& Sterk PJ (1995). The severity of breathlessness during challenges with inhaled methacholine and hypertonic saline in atopic asthmatic subjects. American Journal of Respiratory and Critical Care Medicine, 152: 38-44.

18. Carden DL, Nowak RM, Sarkar D \& Tomlanovich MC (1983). Vital signs including pulsus paradoxus in the assessment of acute bronchial asthma. Annals of Emergency Medicine, 12: 80-83.

19. Shim CS \& Williams Jr MH (1978). Pulsus paradoxus in asthma. Lancet, 1 (8063): 530-531.

20. Knowles GK \& Clark TSH (1973). Pulsus paradoxus as a valuable sign indicating severity of asthma. Lancet, 2: 1356-1359.

21. O'Connor GT \& Weiss ST (1994). Clinical and symptom measures. American Journal of Respiratory and Critical Care Medicine, 149 (Part 2): S21-S28.

22. Bailey WC, Higgins DM, Richards BM \& Richards JM (1992). Asthma severity: a factor analytic investigation. American Journal of Medicine, 93: 263-269. 